

\title{
Use of the Tooth Coronal Pulp Index for Recognition of the Pubertal Growth Period
}

${ }^{1}$ Fehmieh R Nawaya, ${ }^{2}$ Ahmad S Burhan

\begin{abstract}
Aim: The present study aimed to investigate the association between the tooth coronal index (TCl) and the pubertal growth stages (PGS) for children and adolescents.

Materials and methods: A cross-sectional study was performed using retrospectively collected panoramic and hand-wrist radiographs of 262 individuals (125 males, 137 females). The coronal height $(\mathrm{CH})$ and the coronal pulp cavity height $(\mathrm{CPCH})$ of the left mandibular teeth were measured. Then the $\mathrm{TCl}$ for which was calculated according to lkeda et al (1985). The estimated $\mathrm{TCl}$ for individuals with the following PGS after Fishman (1987) are: SMI 4 (S), SMI 5 (DP3 cap), SMI 6 (MP3 cap) and SMI 7 (Mp5 cap). The associations between the TCI and the PGS were investigated by correlation coefficient of Spearman's rho, and the validity values for the PGS were computed.
\end{abstract}

Results: Significant correlations were noted between the simple $\mathrm{TCl}$ values for premolars and molars and the PGS, and the highest correlation was for the summed $\mathrm{TCl}$ for both first and second molars. Utilizing the validity values of the summed $\mathrm{TCl}$ for both first and second mandibular molars, the PGS can be predicted as follows: S stage when $\mathrm{TCl}$ is 49.17 or lesser, DP3cap stage when $\mathrm{TCl}$ is 43.52 or lesser, MP3cap stage when $\mathrm{TCl}$ is 36.73 or lesser, and Mp5cap stage when $\mathrm{TCl}$ is 26.84 or lesser.

Conclusion: The $\mathrm{TCl}$ values declined along with the maturational process in children and adolescents. The TCI for both first and second molars was the best predictor of the PGS.

Clinical significance: Panoramic photographs can be beneficial for prediction of the skeletal maturity and treatment planning without resorting to hand-wrist radiographs.

Keywords: Cross-sectional study, Pubertal growth stages, Tooth coronal index.

\footnotetext{
${ }^{1}$ Department of Pediatric Dentistry, Faculty of Dentistry, Syrian Private University, Damascus Countryside, Syria

${ }^{2}$ Department of Orthodontics, Faculty of Dentistry, Damascus University, Damascus, Syria

Corresponding Author: Ahmad S Burhan, Department of Orthodontics, Faculty of Dentistry, Damascus University, Damascus Syria, Phone: +963944302075, e-mail: dr.burhan-a@hotmail.com
}

How to cite this article: Nawaya FR, Burhan AS. Use of the Tooth Coronal Pulp Index for Recognition of the Pubertal Growth Period. J Contemp Dent Pract 2016;17(11):884-889.

\section{Source of support: Nil}

\section{Conflict of interest: None}

\section{INTRODUCTION}

Age estimation is an important requisite in clinical practice, especially for growing patients. This estimation is essential to decide timing of the orthodontic treatment, which conducts to brief treatment period and more stable outcome. $^{1}$

The chronological age is clarified by birth date, ${ }^{2}$ but it is not considered as an acceptable predictor of skeletal maturation due to the developmental variations among individuals. ${ }^{3}$ In spite of the fact that growth of body frequently deviates to the chronological age, it relates well to skeletal age. ${ }^{4}$ The skeletal maturity state of a patient assists to know the amount of growth remaining or timing of the pubertal growth spurt. ${ }^{3,5}$ The most popular skeletal age evaluation tool is the hand-wrist radiograph, which depends on the stages of bone maturation that can be determined by the visual inspection of developing bones at several ossification centers of the hand. ${ }^{6-8}$ In spite of the high acceptable accuracy of this record, they were questionable because of the further radiation exposure. ${ }^{3}$ Attempting to exempt this additional record, many investigators tried to use the lateral cephalographs, which is already obtained as a routine record for diagnosis, to detect the skeletal maturation using cervical vertebrae., ${ }^{9,10}$

Since the dental age is a possible indicator for skeletal maturation, ${ }^{11,12}$ several techniques have been developed in order to estimate the dental age using panoramic radiographs. These radiographs have the advantage of showing all the maxillary and mandibular teeth on a single film. ${ }^{13}$ Various features were studied, such as mineralization of developing permanent teeth by Moorrees et $\mathrm{al}^{14}$ and 
Demirjian et $\mathrm{al}^{15}$; third molar development by Harris and Nortje $^{16}$; secondary dentin deposition by Kvaal et $\mathrm{al}^{17}$ and Drusini ${ }^{18}$; pulp/tooth area ratio by Cameriere et $\mathrm{al}^{19}$; tooth-coronal index (TCI) by Ikeda et $\mathrm{al}^{13}$ and Drusini et $\mathrm{al}^{20}$; open apices by Cameriere et $\mathrm{al}^{21}$

Among the assessed features, the TCI developed by Ikeda et $\mathrm{al}^{13}$ has been lesser but has not been estimated on different ethnical groups. In this technique, the coronal height $(\mathrm{CH})$ and the coronal pulp cavity height $(\mathrm{CPCH})$ of teeth are measured. Then, the TCI is calculated for each tooth using the following formula $[\mathrm{TCI}=\mathrm{CPCH} / \mathrm{CH} \times$ 100] and regressed on the real age of the sample. Drusini et $\mathrm{al}^{20}$ and Karkhanis et $\mathrm{al}^{22}$ followed the established technique of Ikeda et $\mathrm{al}^{13}$ and verified the negative correlation between the TCI and the chronological age.

No previous study tried to correlate between this index and the pubertal growth stage (PGS). Therefore, the current study attempts to recognize the PGS utilizing panoramic radiographs. The aim of this study was to assess the TCI in children and adolescents, and to define the relation between the TCI and the PGS.

\section{MATERIALS AND METHODS}

This analytical cross-sectional study comprised digital panoramic and left hand-wrist radiographs of 262 Syrian individuals (125 males, 137 females) collected between August 2013 and January 2016 from the archive of Orthodontic Department of Dental School in Damascus University, Syria. For the studied sample, the age for males ranged from 10.22 to 16.01 years (mean $14.61 \pm$ SD 1.26), while for females it was between 9.03 and 14.39 years (mean $12.58 \pm$ SD 1.68).

The inclusion criteria include good panoramic and hand-wrist radiographs taken simultaneously from the same individual who had normal growth. Exclusion criteria were abnormal dental conditions, such as transposition, impaction, missing, supernumerary teeth, or retained deciduous teeth. Also teeth with caries, fillings, root canal treatment, crowns, pathologies, or attrition were excluded. In addition, individuals with severe periodontitis, systemic illness, nutritional or endocrine problems, previous history of orthodontic treatment, or history of trauma were not included in the current study.

The panoramic and hand-wrist radiographs for each individual were coded, then they were evaluated by the two authors separately using image processing software (Millensys, MiViewer, version 10.4) to the nearest $0.01 \mathrm{~mm}$. The measurements for the left mandibular incisors, canine, premolars, and first and second molars were evaluated on panoramic radiographs according to Ikeda et al. ${ }^{13}$ For each tooth, a straight line was drawn between the mesial and distal cementoenamel junction points. Following that, $\mathrm{CH}$ was measured perpendicularly from
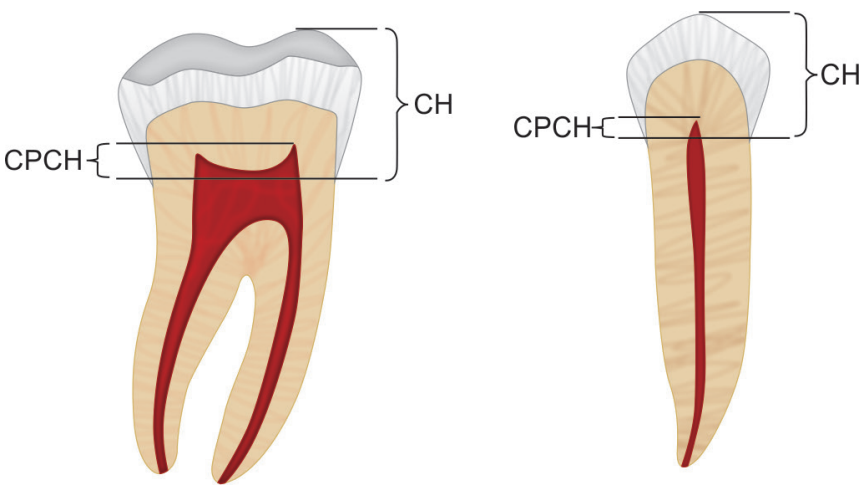

Fig. 1: The liner measurements demanded for calculation of the $\mathrm{TCl}$

the drawn cervical line to the tip of the highest cusp of tooth, and $\mathrm{CPCH}$ was measured perpendicularly from the drawn cervical line to the tip of the highest pulp horn of tooth (Fig. 1). After that, the TCI was computed as follows: $\mathrm{TCI}=\mathrm{CPCH} / \mathrm{CH} \times 100$. Since the TCI is the CPCH-to-CH ratio, which is founded on two linear measurements assessed on the same site on the radiograph, there is no need for standardization of tooth size.

The left hand-wrist radiographs were assessed according to the system of skeletal maturation assessment presented by Fishman in a more accurate manner for rating the skeletal age in which 11 skeletal maturity indicators (SMI) had been included. ${ }^{6}$ The current study was confined to the following maturational stages that cover the pubertal growth period $^{23}$ : SMI 4 is based on the ossification of the adductor sesamoid of the thumb (S) (31 males, 34 females), SMI 5 on the capping of the epiphysis of the distal phalanx of the third finger (DP3 cap) (30 males, 32 females), SMI 6 on the capping of the epiphysis of the middle phalanx of the third finger (MP3 cap) (31 males, 35 females), and SMI 7 on the capping of the epiphysis of the middle phalanx of the fifth finger (Mp5 cap) (33 males, 36 females).

\section{Sample Size Estimation}

The sample size was established using $G^{*}$ Power software, version 3.0.6 (Franz Faul, Universität Kiel, Germany) with one-way analysis of variance (ANOVA), a selected study power of $90 \%$, a number of groups of 4 , a significance level of 0.05 , and an effect size of 0.25 . The analysis revealed that 58 individuals were demanded in each group.

\section{Statistical Analysis}

Our data were analyzed using Statistical Package for the Social Sciences (SPSS) software version 20 (IBM SPSS Statistics, Armonk, NY: IBM Corp., USA). The reliability of the interexaminer measurements was calculated by the intraclass correlation coefficient.

The distribution of our data was studied using onesample Kolmogorov-Smirnov test. The comparisons 
Table 1: Descriptive statistics and normality distribution for the $\mathrm{TCl}$ values of teeth according to gender

\begin{tabular}{|c|c|c|c|c|c|c|c|c|c|c|c|c|}
\hline \multirow{2}{*}{$\begin{array}{l}\text { Tooth } \\
\text { (FDI) }\end{array}$} & \multicolumn{4}{|c|}{ Males } & \multicolumn{4}{|c|}{ Females } & \multicolumn{4}{|c|}{ Total } \\
\hline & Mean & $S D$ & ${ }^{t} K-S$ & ${ }^{t} p$-value & Mean & $S D$ & ${ }^{t} K-S$ & ${ }^{t} p$-value & Mean & $S D$ & ${ }^{t} K-S$ & ${ }^{t} p$-value \\
\hline 31 & 20.49 & 3.38 & 0.718 & 0.681 & 20.18 & 3.46 & 0.677 & 0.748 & 20.33 & 3.38 & 0.885 & 0.414 \\
\hline 32 & 22.35 & 5.40 & 0.710 & 0.695 & 22.00 & 4.59 & 0.465 & 0.982 & 22.17 & 4.95 & 0.674 & 0.755 \\
\hline 33 & 23.30 & 4.12 & 0.775 & 0.585 & 26.36 & 7.54 & 0.867 & 0.440 & 24.83 & 6.19 & 0.924 & 0.360 \\
\hline 34 & 25.94 & 6.67 & 0.471 & 0.980 & 26.67 & 7.56 & 0.369 & 0.999 & 26.31 & 7.05 & 0.436 & 0.991 \\
\hline 35 & 24.85 & 6.23 & 0.694 & 0.722 & 25.89 & 6.44 & 0.552 & 0.921 & 25.37 & 6.28 & 0.558 & 0.915 \\
\hline 36 & 25.28 & 5.06 & 0.464 & 0.983 & 24.80 & 7.23 & 0.585 & 0.883 & 25.04 & 6.17 & 0.591 & 0.877 \\
\hline 37 & 21.40 & 5.63 & 0.520 & 0.950 & 21.17 & 4.91 & 0.543 & 0.930 & 21.28 & 5.22 & 0.493 & 0.968 \\
\hline
\end{tabular}

$\mathrm{TCl}$ : Tooth coronal index; ; SD: Standard deviation; ${ }^{\dagger}$ Using Kolmogorov-Smirnov test

were made between the values for males and females with regard to measurements of each tooth individually using two-sample t-test. The means of the TCI for the left mandibular teeth in the four stages of the pubertal growth were compared by one-way ANOVA to investigate differences. Then, the post hoc Tukey's test was performed to investigate groups having differences. The Spearman's rho correlation coefficient was used to investigate the correlations between the TCI values and the PGS. To study the possibility of identifying each PGS depending on the $\mathrm{TCI}$, the amounts of space under the curves of receiver operating characteristic were computed, and the validity values for the PGS according to the summed TCI for the mandibular molars were calculated. A p-value of 0.05 or less was accounted significant.

\section{RESULTS}

The interexaminer correlation coefficients in this study varied from 0.86 to 0.97 , expressing good correlations of measurements. The TCI values of the left mandibular teeth were dispensed naturally (Table 1). It was observed that there were no differences between the TCI values for males and females (Table 2). Thus, these data were integrated in all subsequent comparisons.

Table 3 shows that there were no differences in the TCI values for incisors between the PGS groups, while it displays differences in the TCI values for the rest of

Table 2: Differences in the TCl values of the left mandibular teeth between the male and female

\begin{tabular}{|c|c|c|c|c|c|c|}
\hline \multirow{2}{*}{$\begin{array}{l}\text { Tooth } \\
\text { (FDI) }\end{array}$} & \multirow{2}{*}{$\begin{array}{l}\text { Mean } \\
\text { difference }\end{array}$} & \multirow[b]{2}{*}{$S D$} & \multicolumn{2}{|c|}{$\begin{array}{l}\text { Levene's test } \\
\text { for equality of } \\
\text { variances }\end{array}$} & \multicolumn{2}{|c|}{$\begin{array}{c}\text { Two samples } \\
\text { t-test for equality } \\
\text { of means }\end{array}$} \\
\hline & & & F-value & $p$-value & $t$-value & $p$-value \\
\hline 31 & 0.31 & 1.08 & 0.021 & 0.886 & 0.283 & 0.778 \\
\hline 32 & 0.35 & 1.58 & 0.920 & 0.344 & 0.222 & 0.825 \\
\hline 33 & -3.06 & 1.92 & 3.557 & 0.067 & -1.594 & 0.119 \\
\hline 34 & -0.73 & 2.25 & 0.345 & 0.560 & -0.323 & 0.748 \\
\hline 35 & -1.04 & 2.00 & 0.262 & 0.612 & -0.521 & 0.605 \\
\hline 36 & 0.48 & 1.97 & 2.307 & 0.137 & 0.245 & 0.808 \\
\hline 37 & 0.23 & 1.67 & 0.000 & 0.982 & 0.135 & 0.893 \\
\hline
\end{tabular}

TCI: Tooth coronal index; SD: Standard deviation
Table 3: Differences in the TCI values between the PGS

\begin{tabular}{|c|c|c|c|c|c|}
\hline Tooth (FDI) & Stage & Mean & $S D$ & ${ }^{\infty} F$-value & ${ }^{\infty} p$-value \\
\hline \multirow[t]{4}{*}{31} & $S$ & 20.00 & 3.35 & 3.139 & 0.057 \\
\hline & DP3cap & 19.82 & 2.24 & & \\
\hline & MP3cap & 18.69 & 2.45 & & \\
\hline & MP5cap & 22.82 & 4.12 & & \\
\hline \multirow[t]{4}{*}{32} & $\mathrm{~S}$ & 21.22 & 2.60 & 2.498 & 0.075 \\
\hline & DP3cap & 23.45 & 5.86 & & \\
\hline & MP3cap & 19.37 & 4.68 & & \\
\hline & MP5cap & 24.64 & 4.99 & & \\
\hline \multirow[t]{4}{*}{33} & $\mathrm{~S}$ & 30.53 & 8.59 & 7.081 & $<0.001^{* * *}$ \\
\hline & DP3cap & 23.72 & 3.45 & & \\
\hline & MP3cap & 20.16 & 2.88 & & \\
\hline & MP5cap & 24.91 & 3.25 & & \\
\hline \multirow[t]{4}{*}{34} & $S$ & 31.35 & 4.09 & 3.378 & $0.029^{*}$ \\
\hline & DP3cap & 26.51 & 10.41 & & \\
\hline & MP3cap & 22.41 & 4.15 & & \\
\hline & MP5cap & 24.96 & 5.06 & & \\
\hline \multirow[t]{4}{*}{35} & $S$ & 27.49 & 5.89 & 3.810 & $0.018^{*}$ \\
\hline & DP3cap & 29.11 & 5.65 & & \\
\hline & MP3cap & 21.60 & 3.67 & & \\
\hline & MP5cap & 23.28 & 7.03 & & \\
\hline \multirow[t]{4}{*}{36} & S & 30.14 & 4.51 & 5.267 & $0.004^{\star *}$ \\
\hline & DP3cap & 25.62 & 4.32 & & \\
\hline & MP3cap & 21.05 & 7.73 & & \\
\hline & MP5cap & 23.34 & 3.98 & & \\
\hline \multirow[t]{4}{*}{37} & $S$ & 24.83 & 2.64 & 3.611 & $0.022^{*}$ \\
\hline & DP3cap & 22.37 & 7.19 & & \\
\hline & MP3cap & 18.87 & 2.92 & & \\
\hline & MP5cap & 19.07 & 4.83 & & \\
\hline \multirow[t]{4}{*}{$(34,35,36,37)$} & $\mathrm{S}$ & 113.82 & 13.44 & 6.863 & $<0.001^{* * *}$ \\
\hline & DP3cap & 103.62 & 19.75 & & \\
\hline & MP3cap & 83.92 & 12.98 & & \\
\hline & MP5cap & 90.65 & 17.27 & & \\
\hline \multirow[t]{4}{*}{$(36,37)$} & $S$ & 54.98 & 5.44 & 7.096 & $<0.001^{* * *}$ \\
\hline & DP3cap & 47.99 & 10.04 & & \\
\hline & MP3cap & 39.91 & 8.04 & & \\
\hline & MP5cap & 42.40 & 7.56 & & \\
\hline
\end{tabular}

TCI: Tooth coronal index; PGS Pubertal growth stages; ${ }^{\infty}$ Using the one-way ANOVA test; SD: standard deviation; S: The stage based on the ossification of the adductor sesamoid of the thumb; DP3cap: The stage based on the capping of the epiphysis of the distal phalanx of the third finger; MP3cap: The stage based on the capping of the epiphysis of the middle phalanx of the third finger; MP5cap: The stage based on the capping of the epiphysis of the middle phalanx of the fifth finger; ${ }^{*} p \leq 0.05 ;{ }^{* *} p \leq 0.01 ;{ }^{* * *} p \leq 0.001$ 
Use of the Tooth Coronal Pulp Index for Recognition of the Pubertal Growth Period

teeth and the dental groups between the PGS groups. These findings revealed that there were, at least, differences between two groups. To detect these groups, multiple comparisons were fulfilled (Table 4).

There was no significant correlation between the TCI values for incisors and canine and the PGS, while significant correlations were observed for premolars and molars. The correlation coefficients were the highest for first and second molars. Thus, the correlation between the summed TCI for premolars and molars and the summed TCI for both first and second molars with the PGS were assessed. It was found that the correlation coefficients rose when gathering the TCI values, and the highest correlation was between the summed TCI for both first and second molars and the PGS (Table 5).

Noticing the amounts of space under the receiver operating characteristic curves of the summed TCI for both first and second mandibular molars, it can be manifested that the degree of identification for the S stage was high, the MP3cap stage was medium, and the Mp5cap and DP3cap stages were low (Table 6). Observing the top values of validity, which are the sum of sensitivity and specificity, it can be seen that $\mathrm{S}$ stage is predictable when TCI is 49.17 or lesser, DP3cap stage is predictable when TCI is 43.52 or lesser, MP3cap stage is predictable when TCI is 36.73 or lesser, and Mp5cap stage is predictable when TCI is 26.84 or lesser.

\section{DISCUSSION}

The assessment of skeletal age provides insight for recognizing the stage of development progression during childhood and adolescence regardless of chronological age. Therefore, it can be used for comparing between children and planning for orthodontic treatment. ${ }^{23}$ To the best of our knowledge, the current research is the first study investigating the relation between the PGS and the TCI in children and adolescents using panoramic radiographs, which are a common diagnostic records in dental practices. This might be useful for exempting hand-wrist radiographs.

The panoramic and left hand-wrist radiographs in the current study were coded to keep away from bias, then the two authors assessed them independently. The interexaminer correlation coefficients ranged from 0.86 to 0.97 ; thus, our results are reliable. In this study, the TCI was calculated using the mandibular teeth because they are
Table 4: Multiple comparisons in the TCI values between the PGS

\begin{tabular}{|c|c|c|c|c|c|}
\hline $\begin{array}{l}\text { Tooth } \\
\text { (FDI) }\end{array}$ & Variables & & $\begin{array}{l}\text { Mean } \\
\text { difference }\end{array}$ & $\begin{array}{l}\text { Standard } \\
\text { error }\end{array}$ & ${ }^{\Omega} p$-value \\
\hline \multirow[t]{6}{*}{33} & \multirow[t]{3}{*}{ MP5cap } & $S$ & -5.62 & 2.29 & 0.084 \\
\hline & & DP3cap & 1.19 & 2.29 & 0.954 \\
\hline & & MP3cap & 4.75 & 2.29 & 0.180 \\
\hline & \multirow[t]{2}{*}{ MP3cap } & $S$ & -10.37 & 2.29 & $<0.001^{* * *}$ \\
\hline & & DP3cap & -3.56 & 2.29 & 0.416 \\
\hline & DP3cap & S & -6.81 & 2.29 & $0.025^{*}$ \\
\hline \multirow[t]{6}{*}{34} & \multirow[t]{3}{*}{ MP5cap } & $S$ & -6.39 & 2.90 & 0.141 \\
\hline & & DP3cap & -1.55 & 2.90 & 0.950 \\
\hline & & MP3cap & 2.56 & 2.90 & 0.814 \\
\hline & \multirow[t]{2}{*}{ MP3cap } & $\mathrm{S}$ & -8.95 & 2.90 & $0.019^{*}$ \\
\hline & & DP3cap & -4.11 & 2.90 & 0.498 \\
\hline & DP3cap & $\mathrm{s}$ & -4.85 & 2.90 & 0.353 \\
\hline \multirow[t]{6}{*}{35} & \multirow[t]{3}{*}{ MP5cap } & $S$ & -4.21 & 2.55 & 0.363 \\
\hline & & DP3cap & -5.83 & 2.55 & 0.119 \\
\hline & & MP3cap & 1.68 & 2.55 & 0.912 \\
\hline & \multirow[t]{2}{*}{ MP3cap } & $S$ & -5.88 & 2.55 & 0.115 \\
\hline & & DP3cap & -7.51 & 2.55 & $0.027^{*}$ \\
\hline & DP3cap & $S$ & 1.63 & 2.55 & 0.918 \\
\hline \multirow[t]{6}{*}{36} & \multirow[t]{3}{*}{ MP5cap } & $S$ & -6.80 & 2.39 & $0.035^{*}$ \\
\hline & & DP3cap & -2.28 & 2.39 & 0.776 \\
\hline & & MP3cap & 2.30 & 2.39 & 0.773 \\
\hline & \multirow[t]{2}{*}{ MP3cap } & $S$ & -9.10 & 2.39 & $0.003^{* *}$ \\
\hline & & DP3cap & -4.58 & 2.39 & 0.241 \\
\hline & DP3cap & $S$ & -4.52 & 2.39 & 0.251 \\
\hline \multirow[t]{6}{*}{37} & \multirow{3}{*}{ MP5cap } & $S$ & -5.77 & 2.13 & $0.048^{*}$ \\
\hline & & DP3cap & -3.30 & 2.13 & 0.418 \\
\hline & & MP3cap & 0.20 & 2.13 & 1.000 \\
\hline & \multirow[t]{2}{*}{ MP3cap } & $S$ & -5.97 & 2.13 & $0.039^{*}$ \\
\hline & & DP3cap & -3.50 & 2.13 & 0.366 \\
\hline & DP3cap & $S$ & -2.46 & 2.13 & 0.657 \\
\hline \multirow{6}{*}{$\begin{array}{l}(34,35 \\
36,37)\end{array}$} & \multirow[t]{3}{*}{ MP5cap } & $S$ & -23.17 & 7.20 & $0.014^{*}$ \\
\hline & & DP3cap & -12.97 & 7.20 & 0.290 \\
\hline & & MP3cap & 6.72 & 7.20 & 0.787 \\
\hline & \multirow[t]{2}{*}{ MP3cap } & $S$ & -29.90 & 7.20 & $<0.001^{* * *}$ \\
\hline & & DP3cap & -19.69 & 7.20 & $0.045^{\star}$ \\
\hline & DP3cap & $S$ & -10.20 & 7.20 & 0.498 \\
\hline \multirow[t]{6}{*}{$(36,37)$} & \multirow[t]{3}{*}{ MP5cap } & $S$ & -12.57 & 3.55 & $0.006^{* *}$ \\
\hline & & DP3cap & -5.59 & 3.55 & 0.406 \\
\hline & & MP3cap & 2.49 & 3.55 & 0.896 \\
\hline & \multirow[t]{2}{*}{ MP3cap } & $S$ & -15.07 & 3.55 & $<0.001^{* * *}$ \\
\hline & & DP3cap & -8.08 & 3.55 & 0.123 \\
\hline & DP3cap & $\mathrm{S}$ & -6.99 & 3.55 & 0.219 \\
\hline
\end{tabular}

TCl: Tooth coronal index; PGS Pubertal growth stages; ${ }^{\Omega}$ Using the Tukey HSD test; SD: standard deviation; S: The stage based on the ossification of the adductor sesamoid of the thumb; DP3cap: The stage based on the capping of the epiphysis of the distal phalanx of the third finger; MP3cap: The stage based on the capping of the epiphysis of the middle phalanx of the third finger; MP5cap: The stage based on the capping of the epiphysis of the middle phalanx of the fifth finger; ${ }^{*} p \leq 0.05,{ }^{* *} p \leq 0.01,{ }^{* * *} p \leq 0.001$

Table 5: Correlation coefficient (Spearman's rho) between the TCI values and the PGS for the total sample

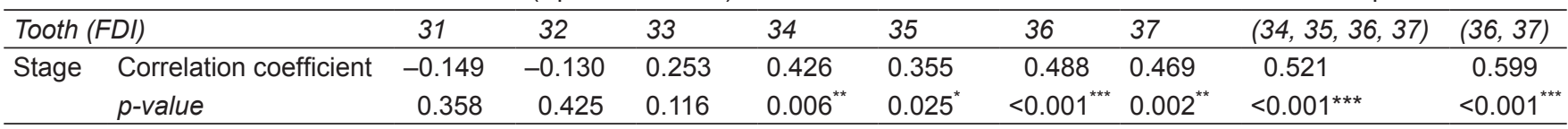

TCI: Tooth coronal index; PGS: Pubertal growth stages; ${ }^{*} p \leq 0.05 ;{ }^{* \star} p \leq 0.01 ;{ }^{* \star *} p \leq 0.001$ 
Table 6: Areas under the receiver operating characteristic based on the TCl values of the left mandibular molars in different PGS

\begin{tabular}{lllll}
\hline Stage & Area & $\begin{array}{l}\text { Standard } \\
\text { error }\end{array}$ & $\begin{array}{l}\text { Asymptotic } \\
\text { significance }\end{array}$ & Discrimination \\
\hline S & 0.900 & 0.049 & 0.000 & high \\
DP3cap & 0.653 & 0.108 & 0.048 & low \\
MP3cap & 0.223 & 0.081 & 0.010 & medium \\
MP5cap & 0.323 & 0.087 & 0.043 & low \\
\hline
\end{tabular}

TCI: Tooth coronal index; PGS: Pubertal growth stages; S: The stage based on the ossification of the adductor sesamoid of the thumb; DP3cap: The stage based on the capping of the epiphysis of the distal phalanx of the third finger; MP3cap: The stage based on the capping of the epiphysis of the middle phalanx of the third finger; MP5cap: The stage based on the capping of the epiphysis of the middle phalanx of the fifth finger

easily visible, which could guarantee only sound teeth were measured. The left side of the mandible was considered because most previous studies reported that differences between tooth side is disregarded at radiographic age estimation. ${ }^{22,24}$ Considering the clinical significance, the current study was restrained to the stages covering the pubertal growth period: S, DP3 cap, MP3 cap, and $\mathrm{Mp} 5$ cap. In these stages, children represented the very high growth speed. ${ }^{23}$

The current results showed that there were no differences in the TCI values between males and females. Therefore, the data were combined. These findings were in agreement with the data reported in Western Australia by Karkhanis et al. ${ }^{22}$ In contrast to our findings, some studies in Japan ${ }^{25}$ and Malawi ${ }^{24}$ mentioned that gender had a significant influence on the TCI values. They attributed these differences to the effect of estrogen on formation of secondary dentin.

There were negative correlations between the simple TCI values for premolars and molars and the PGS in the present study. These results could be attributed to secondary dentin deposition which is a continuous process leading to reduction of the dental pulp chamber size with increasing age. These findings are in line with those of Drusini et $\mathrm{al}^{20}$ in Italy; Igbigbi and Nyirenda ${ }^{24}$ in Malawi; Karkhanis et $\mathrm{al}^{22}$ in Western Australia, and Talabani et $\mathrm{al}^{26}$ in Iraq, who mentioned that negative correlations between the TCI and the chronological age were recorded.

For the correlations between the simple TCI of each tooth and the PGS, the highest correlations were for first and second molars. In contrast to our finding, Igbigbi and Nyirenda ${ }^{24}$ in Malawi declared that the correlation was greater for premolar than molar teeth. These differences could be explained by ethnic and genetic differences. It was also observed that the correlation coefficient between the TCI values and the PGS increased when the summed TCI values were used, and the highest correlation was with the summed TCI for both first and second molars.
These findings are in line with those of Karkhanis et $\mathrm{al}^{22}$ in Western Australia, who demonstrated that the accuracy of age estimation using the TCI rose when multiple linear regression models were used compared to simple regressions.

It is of interest to note that the summed TCI for mandibular molars can be used to assign the PGS of children, and the degree of identification for the $S$ stage was high, the MP3cap stage was medium, and the Mp5cap and DP3cap stages were low. Considering the top values of the validity for the PGS according to the summed TCI for both first and second molars, it would be possible to classify individuals into maturational stages of $\mathrm{S}(\mathrm{TCI} \leq$ 49.17), DP3cap (TCI $\leq 43.52)$, MP3cap (TCI $\leq 36.73)$, and Mp5cap (TCI $\leq 26.84)$. Thus, the TCI is a feasible and simple method for the PGS recognition. However, it is important to note that these findings are only applicable to Syrian children and adolescents, and further studies with different populations are required in order to devise customized values for each one.

\section{CONCLUSION}

- The TCI values concurrently decreased with development progression in children and adolescents.

- Gender had no influence on the TCI values.

- The simple TCI for first and second mandibular molars were the most relevant with the PGS compared to those of the rest of teeth.

- Gathering the TCI values improved the PGS prediction, and the best indicator was with the summed TCI for both first and second mandibular molars. The PGS can be predicted according to this TCI as follows: $\mathrm{S}$ stage when the TCI is 49.17 or lesser, DP3cap stage when the TCI is 43.52 or lesser, MP3cap stage when the TCI is 36.73 or lesser, and Mp5cap stage when the TCI is 26.84 or lesser.

\section{CLINICAL SIGNIFICANCE}

Panoramic photographs provide an opportunity to identify the PGS using the TCI for predicting skeletal maturity. They help us make further therapeutic decisions without need to obtain hand-wrist radiographs; thus, exposure to radiation during treatment would be lesser. It is recommended that the assessment of skeletal maturity be based on the summed TCI values for both first and second mandibular molars.

\section{REFERENCES}

1. Sukhia RH, Fida M, Azam SI. Dental age table for a sample of Pakistani children. Eur J Orthod 2012 Feb;34(1):77-82.

2. Frucht S, Schnegelsberg C, Schulte-Mönting J, Rose E, Jonas I. Dental age in Southwest Germany: a radiographic study. J Orofac Orthop 2000;61(5):318-329. 
3. Chen J, Hu H, Guo J, Liu Z, Liu R, Li F, Zou S. Correlation between dental maturity and cervical vertebral maturity. Oral Surg Oral Med Oral Pathol Oral Radiol Endod 2010 Dec;110(6):777-783.

4. Perinetti G, Contardo L, Gabrieli P, Baccetti T, Di Lenarda R. Diagnostic performance of dental maturity for identification of skeletal maturation phase. Eur J Orthod 2012 Aug;34(4):487-492.

5. Kumar S, Singla A, Sharma R, Virdi MS, Anupam A, Mittal B. Skeletal maturation evaluation using mandibular second molar calcification stages. Angle Orthod 2012 May;82(3):501-506.

6. Fishman LS. Radiographic evaluation of skeletal maturation: a clinically oriented method based on hand-wrist films. Angle Orthod 1982 Apr;52(2):88-112.

7. Grave K, Brown T. Skeletal ossification and the adolescent growth spurt. Am J Orthod 1976 Jun;69(6):611-619.

8. Krailassiri S, Anuwongnukroh N, Dechkunakorn S. Relationships between dental calcification stages and skeletal maturity indicators in Thai individuals. Angle Orthod 2002 Apr;72(2):155-166.

9. Hassel B, Farman AG. Skeletal maturation evaluation using cervical vertebrae. Am J Orthod Dentofacial Orthop 1995 Jan;107(1):58-66.

10. Mahajan S. Evaluation of skeletal maturation by comparing the hand-wrist radiograph and cervical vertebrae as seen in lateral cephalogram. Indian J Dent Res 2011 Mar-Apr;22(2): 309-316.

11. Lopes LJ, de Oliveira Gamba T, Visconti MAPG, Ambrosano GMB, Haiter-Neto F, Freitas DQ. Utility of panoramic radiography for identification of the pubertal growth period. Am J Orthod Dentofacial Orthop 2016 Apr;149(4):509-515.

12. Shilpa P, Sunil R, Sapna K, Kumar N. Estimation and comparison of dental, skeletal and chronologic age in Bangalore south school going children. J Indian Soc Pedod Prev Dent 2013 Apr-Jun;31(2):63-68.

13. Ikeda N, Umetsu K, Kashimura S, Suzuki T, Oumi M. Estimation of age from teeth with their soft X-ray findings. Nihon Hoigaku Zasshi 1985 Jun;39(3):244-250.
14. Moorrees CF, Fanning EA, Hunt Jr, EE. Age variation of formation stages for ten permanent teeth. J Dent Res 1963 Nov-Dec;42:1490-1502.

15. Demirjian A, Goldstein H, Tanner J. A new system of dental age assessment. Hum Biol 1973 May;45(2):211-227.

16. Harris $M$, Nortje $C$. The mesial root of the third mandibular molar. A possible indicator of age. J Forensic Odontostomatol 1984 Jul-Dec;2(2):39-43.

17. Kvaal SI, Kolltveit KM, Thomsen IO, Solheim T. Age estimation of adults from dental radiographs. Forensic Sci Int. 1995 Jul 28;74(3):175-185.

18. Drusini AG. Age estimation from teeth using soft X-ray findings. Anthropol Anz 1993 Mar;51(1):41-46.

19. Cameriere R, De Luca S, Alemán I, Ferrante L, Cingolani M. Age estimation by pulp/tooth ratio in lower premolars by orthopantomography. Forensic Sci Int 2012 Jan;214(1-3):105-112.

20. Drusini AG, Toso O, Ranzato C. The coronal pulp cavity index: a biomarker for age determination in human adults. Am J Phys Anthropol 1997 Jul;103(3):353-363.

21. Cameriere R, Ferrante L, Cingolani M. Age estimation in children by measurement of open apices in teeth. Int J Legal Med 2006 Jan;120(1):49-52.

22. Karkhanis S, Mack P, Franklin D. Age estimation standards for a Western Australian population using the coronal pulp cavity index. Forensic Sci Int 2013 Sep;231(1-3):412.e1-6.

23. Fishman LS. Maturational patterns and prediction during adolescence. Angle Orthod 1987 Jul;57(3):178-193.

24. Igbigbi P, Nyirenda SK. Age estimation of Malawian adults from dental radiographs. West Afr J Med 2005 Oct-Dec;24(4): 329-333.

25. Agematsu $\mathrm{H}$, Someda $\mathrm{H}$, Hashimoto M, Matsunaga S, Abe S, Kim H-J, et al. Three-dimensional observation of decrease in pulp cavity volume using micro-CT: age-related change. Bull Tokyo Dent Coll 2010;51(1):1-6.

26. Talabani RM, Baban MT, Mahmood MA. Age estimation using lower permanent first molars on a panoramic radiograph: a digital image analysis. J Forensic Dent Sci 2015 May-Aug;7(2):158-162. 